$01.1 ; 06.1 ; 11.2$

\title{
Метод моделирования диэлектрической проницаемости анизотропного иерархически построенного нанокомпозита с периодической структурой
}

\author{
(C) C.А. Корчагин ${ }^{1}$, Д.В. Терин ${ }^{2}$ \\ ${ }^{1}$ Финансовый университет при Правительстве РФ, Москва, Россия \\ ${ }^{2}$ Саратовский национальный исследовательский государственный университет им. Н.Г. Чернышевского, Саратов, Россия \\ E-mail: SAKorchagin@fa.ru
}

Поступило в Редакцию 12 апреля 2021г.

В окончательной редакции 12 апреля 2021 г.

Принято к публикации 5 мая 2021г.

Предложен метод моделирования комплексной диэлектрической проницаемости анизотропного иерархически построенного нанокомпозита с периодической структурой, основанный на комплексном применении квантово-механических расчетов, модели эффективной среды и эквивалентных схем замещения. Исследована диэлектрическая проницаемость нанокомпозита $\mathrm{TiO}_{2}-\mathrm{Al}_{2} \mathrm{O}_{3}$ при воздействии внешнего высокочастотного электромагнитного излучения. Установлены диапазоны длин волн, при которых наблюдаются резонансные всплески. Показана возможность управления максимумами разностных потерь и резонансными максимумами поглощения за счет изменения геометрических параметров нанокомпозита.

Ключевые слова: диэлектрическая проницаемость, нанокомпозит, математическое моделирование, периодическая структура.

DOI: 10.21883/PJTF.2021.16.51318.18822

Электрофизические свойства нанокомпозитов (диэлектрическая проницаемость, электропроводность) с периодической структурой продолжают активно исследоваться с целью более глубокого понимания фундаментальных явлений взаимодействия электромагнитного поля с веществом и эффективного использования новых композиционных материалов в различных практических приложениях (разработка элементов микроэлектроники, оптических устройств, средств радиолокации и защиты информации и пр.) [1-4]. Компьютерное и математическое моделирование является мощным средством теоретических исследований новых функциональных нанокомпозитов [5,6]. Вычислительный эксперимент позволяет эффективно спланировать геометрическую структуру и состав новых композиционных материалов с заданными электрофизическими свойствами, натурное изготовление которых является трудоемким и дорогостоящим этапом исследования [7,8].

В настоящей работе исследуется анизотропный иерархически построенный нанокомпозит с периодической структурой (рис. 1), который состоит из слоев $n$, включающих блоки, ширина которых $a$ с ростом номера слоя уменьшается в 2 раза. В качестве примера взят нанокомпозит из двух материалов: $\mathrm{TiO}_{2}-\mathrm{Al}_{2} \mathrm{O}_{3}$.

$\mathrm{B}$ рамках исследования рассматривается взаимодействие электромагнитного поля с нанокомпозитом в диапазоне длин волн 200-1000 nm. Важной особенностью исследования комплексной диэлектрической проницаемости иерархически построенных периодических структур является необходимость учета наноразмеров в одних направлениях и микроразмеров в других. Моделиро- вание таких систем сопряжено с некоторыми трудностями, связанными с тем, что на макроскопический подход накладываются определенные ограничения (например, в том случае, когда длина волны внешнего электромагнитного излучения становится сопоставимой с размерами атомов), а квантово-механические методы моделирования слишком трудоемки и требуют высоких вычислительных мощностей.

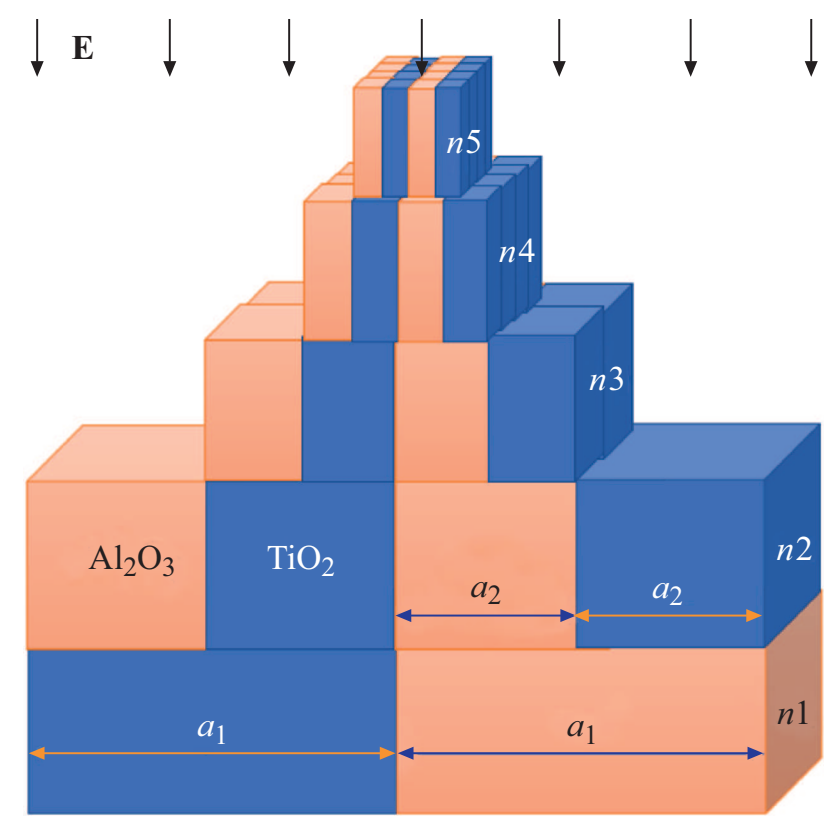

Рис. 1. Компьютерная модель нанокомпозита $\mathrm{TiO}_{2}-\mathrm{Al}_{2} \mathrm{O}_{3}$ с периодической структурой. 
Метод определения диэлектрической проницаемости иерархически построенного композита с периодической структурой

\begin{tabular}{|c|c|c|c|c|}
\hline \multirow{2}{*}{ Слой } & \multirow{2}{*}{$\begin{array}{c}\text { Ширина } a \\
\text { блока, } \\
\text { входящего } \\
\text { в слой, nm }\end{array}$} & \multicolumn{3}{|c|}{ Метод определения $\varepsilon$} \\
\hline & & для блока & для слоя & для всего нанокомпозита \\
\hline $\begin{array}{l}n 5 \\
n 4\end{array}$ & $\begin{array}{c}5 \\
10\end{array}$ & $\begin{array}{c}\text { Квантово- } \\
\text { механический } \\
\text { подход }\end{array}$ & \multirow{2}{*}{$\begin{array}{c}\text { Модель } \\
\text { эффективной среды }\end{array}$} & \multirow{3}{*}{$\begin{array}{c}\text { Метод эквивалентных } \\
\text { схем }\end{array}$} \\
\hline$n 3$ & 20 & \multirow{2}{*}{$\begin{array}{c}\text { Экспериментальные } \\
\text { значения }\end{array}$} & & \\
\hline$n 1$ & 80 & & $\begin{array}{c}\text { Метод } \\
\text { эквивалентных } \\
\text { схем }\end{array}$ & \\
\hline
\end{tabular}
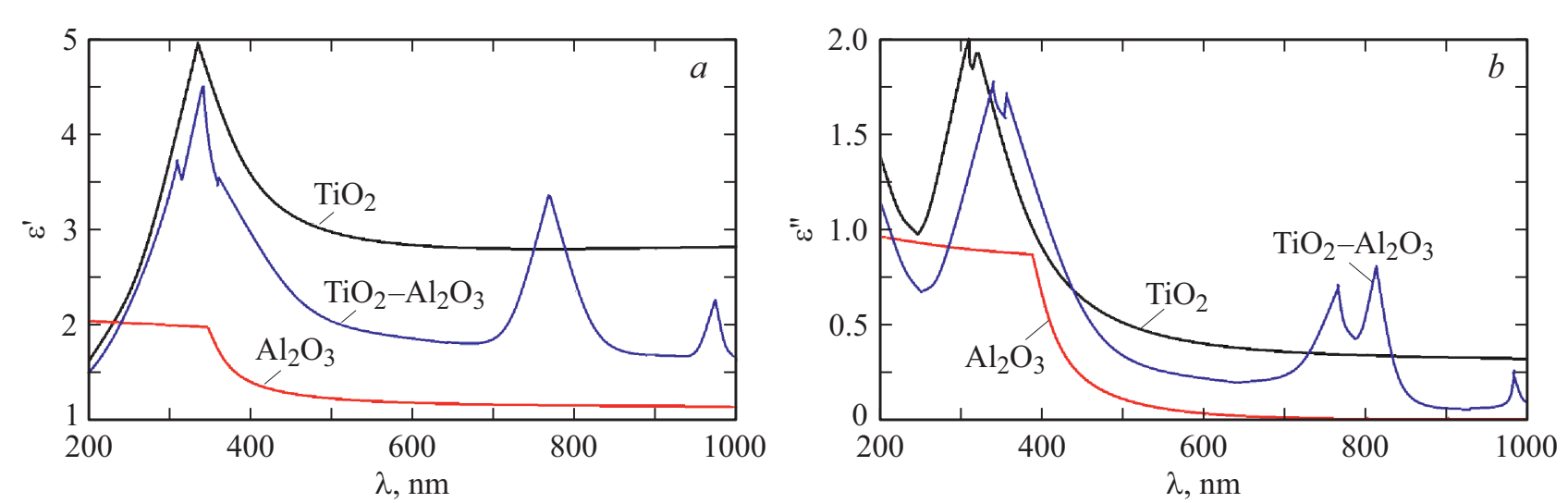

Рис. 2. Зависимости комплексной диэлектрической проницаемости $(a-$ действительная часть, $b-$ мнимая часть $)$ нанокомпозита с периодической структурой от длины волны электромагнитного поля.

В настоящей работе предлагается комбинированный метод определения диэлектрической проницаемости $\varepsilon$ анизотропного нанокомпозита с периодической структурой, который основан на комплексном применении квантово-механических расчетов, модели эффективной среды и эквивалентных схем замещения (см. таблицу).

Для моделирования диэлектрической проницаемости блоков шириной до $10 \mathrm{~nm}$, где необходимо учитывать квантово-размерные эффекты, используется уравнение, предложенное в работе [9] и адаптированное для исследуемой структуры:

$$
\varepsilon(\omega, \mathbf{k})=\frac{4 \pi e^{2}}{V} \sum_{i} \frac{Z_{i}}{\left(\omega-\omega_{m}+\omega_{n}\right)^{2}},
$$

где $\varepsilon-$ диэлектрическая проницаемость блока, $V$ объем блока, $\mathbf{k}=\frac{2 \pi}{\lambda}-$ волновой вектор, $\omega-$ частота внешнего электромагнитного излучения, $\omega_{n}-$ частота перехода из основного состояния молекулы, $\omega_{m}$ - частота перехода из возбужденного состояния молекулы, $Z_{i}$ - эффективный заряд моды $i$. Для проведения моделирования необходима информация о базисе собственных волновых функций и собственных значений гамильтониана рассчитываемых структур. Для их получения используются теория функционала плотности, программный пакет Quantum ESPRESSO и кластер на графических видеоадаптерах NVIDIA GeForce GTX 1060.

Для блоков шириной 20-80 nm в качестве исходных данных по диэлектрической проницаемости используются экспериментально полученные электрофизические свойства материалов [10].

Далее для расчета диэлектрической проницаемости слоев с блоками размером 5-40 nm применялась модель эффективной среды [11]:

$$
\varepsilon=\sum_{j=1}^{n} \varepsilon_{j} a_{j} / \sum_{j=1}^{n} a_{j},
$$

где $\varepsilon_{j}$ - диэлектрическая проницаемость блока $j$. Для определения диэлектрической проницаемости слоев с блоками шириной $80 \mathrm{~nm}$ и нанокомпозита в целом использовались классические уравнения электродинамики и метод эквивалентных схем замещения [12].

На рис. 2 приведены зависимости диэлектрической проницаемости от длины волны внешнего электромаг- 
нитного воздействия для материалов $\mathrm{TiO}_{2}$ и $\mathrm{Al}_{2} \mathrm{O}_{3}$, а также результаты численного моделирования диэлектрической проницаемости иерархически построенного нанокомпозита с периодической структурой. Видно, что в области длин волн $350-370 \mathrm{~nm}$ (электронная поляризация), 750-820 nm (блоховские осцилляции) и 980-1030 nm (поверхностные эффекты) наблюдаются резонансные всплески, которые составляют спектр поглощения и разностных потерь иерархически построенного нанокомпозита с периодической структурой. Варьируя геометрические параметры нанокомпозита, можно управлять максимумами действительной и мнимой частей диэлектрической проницаемости $\mathrm{TiO}_{2}-\mathrm{Al}_{2} \mathrm{O}_{3}$.

Представленный метод позволяет довольно полно исследовать диэлектрическую проницаемость нанокомпозитов с периодической структурой, что может быть полезно при разработке новых материалов с заданными электрофизическими свойствами.

\section{Конфликт интересов}

Авторы заявляют, что у них нет конфликта интересов.

\section{Список литературы}

[1] Y. Zhang, J.R. Choi, S.J. Park, Composites A, 101, 227 (2017). https://doi.org/10.1016/j.compositesa.2017.06.019

[2] P.K. Mishra, Int. J. Eng. Technol. Managem. Res., 5 (2), 315 (2018). https://doi.org/10.29121/ijetmr.v5.i2.2018.663

[3] S. Moussa, F. Namouchi, H. Guermazi, S. Guermazi, Mater. Sci. Eng. B, 266, 115035 (2021). https://doi.org/10.1016/j.mseb.2020.115035

[4] S.A. Korchagin, D.V. Terin, Y.V. Klinaev, S.P. Romanchuk, 2018 Int. Conf. on actual problems of electron devices engineering (APEDE) (IEEE, 2018), p. 397.

DOI: 10.1109/APEDE.2018.8542433

[5] Д.В. Стороженко, В.П. Дзюба, Ю.Н. Кульчин, Письма в ЖТФ, 44 (16), 75 (2018).

DOI: $10.21883 /$ PJTF.2018.16.46479.17127

[6] Н.С. Гинзбург, М.Н. Вилков, Ю.Ю. Данилов, А.П. Конюшков, Л.А. Юровский, Е.В. Иляков, И.С. Кулагин, И.В. Зотова, Письма в ЖТФ, 47 (4), 29 (2021). DOI: $10.21883 /$ PJTF.2021.04.50642.18365

[7] A. Chaurasia, A. Verma, A. Parashar, R.S. Mulik, J. Phys. Chem. C, 123 (32), 20059 (2019). https://doi.org/10.1021/acs.jpcc.9b05965

[8] X. Zhang, H. Wen, Y. Wu, Polymers, 9 (9), 430 (2017). https://doi.org/10.3390/polym9090430

[9] T. Yamamoto, H. Momida, T. Hamada, T. Uda, T. Ohno, Thin Solid Films, 486 (1-2), 136 (2005). https://doi.org/10.1016/j.tsf.2004.11.240

[10] E.D. Palik, Handbook of optical constants of solids (Academic Press, San Diego, 1997).

[11] Л.А. Апресян, Д.В. Власов, Д.А. Задорин, В.И. Красовский, ЖТФ, 87 (1), 10 (2017). DOI: $10.21883 /$ JTF.2017.01.44011.1841

[12] Н.А. Секушин, Н.А. Жук, Л.А. Кокшарова, В.А. Белый, Б.А. Макеев, Д.С. Безносиков, М.В. Ермолина, Письма о материалах, 9 (1), 5 (2019).

DOI: $10.22226 / 2410-3535-2019-1-5-10$ 